\title{
Trusting Intentions towards Robots in Healthcare: A Theoretical Framework
}

\author{
Yvonne O'Connor \\ University College Cork \\ y.oconnor@ucc.ie
}

\author{
Ciara Heavin \\ University College Cork \\ c.heavin@ucc.ie
}

\author{
Mateusz Kupper \\ University College Cork \\ mateusz.kupper@ucc.ie
}

\begin{abstract}
Within the next decade, robots (intelligent agents that are able to perform tasks normally requiring human intelligence) may become more popular when delivering healthcare services to patients. The use of robots in this way may be daunting for some members of the public, who may not understand this technology and deem it untrustworthy. Others may be excited to use and trust robots to support their healthcare needs. It is argued that (1) context plays an integral role in Information Systems (IS) research and (2) technology demonstrating anthropomorphic or system-like features impact the extent to which an individual trusts the technology. Yet, there is little research which integrates these two concepts within one study in healthcare. To address this gap, we develop a theoretical framework that considers trusting intentions towards robots based on the interaction of humans and robots within the contextual landscape of delivering healthcare services. This article presents a theory-based approach to developing effective trustworthy intelligent agents at the intersection of IS and Healthcare.
\end{abstract}

\section{Introduction}

Intelligent agents (e.g. robots) in healthcare are in its infancy, but it is expected to grow exponentially in the next decade [1]. However, literature reveals that users' interactions with intelligent agents trigger contradictory behavioral responses [2]. One perspective is that users assign humanness and social characteristics to intelligent agents and perceive it positively $[3,4]$. Conversely, such systems also trigger perceptions of threat $[5,6]$. According to Rzepka and Benedikt [2] this phenomenon can be explained by the uncanny valley hypothesis $[7,8]$. The uncanny valley is a hypothesized relationship between the degree of an object's resemblance to a human being and the emotional response to such an object [9]. That is, humans have greater affinity to agents that are more realistic whereby this "affinity increases as the agent becomes increasingly realistic, until the agent is semi- realistic, at which point affinity drops dramatically because a partially realistic agent triggers unease in users" [10 p.4785]. Inevitably, this paradoxical relationship with intelligent agents will have an impact on how individuals' trust intelligent agents in healthcare. A dearth of research exists which focuses on the contextual factors that drive the trust of anthropomorphic and/or system-like robotic features in healthcare [11,12].

Existing research has found that the stakeholder category to which the potential user belongs can have an influence on their perceptions of the robot [13]. That means that research examined in one area (e.g. manufacturing) by one stakeholder category (e.g. manufacturing technician) may produce different insights in a different context (e.g. healthcare; patient). In healthcare, this fluctuation can occur if the end user is either an assisted or independent patient, a professional or a person outside the healthcare environment [13]. Additionally, robots are considered expensive technologies to design, develop, and implement for healthcare reasons [14]. It is important that patients to trust robots to ensure long-term continued use thus, providing sufficient return on the initial investment.

The article is structured as follows: Section 2 considers the definitions and characteristics that constitute the term 'intelligent agents'. Section 3 discusses trusting intentions towards robots. To address the existing gap in research, our theoretical framework is presented in Section 4. Section 5 presents our future research plans and we draw our conclusions in Section 6.

\section{Intelligent Agents: Definition and Characteristics}

A simple definition for the term intelligent agents is provided by Charishma and Dhathrika [15 p.15] who define "intelligent agents as agents, capable of flexible autonomous action to meet their design objectives". Intelligent agents can be "software or hardware entities that interact with an external 
environment in an intelligent way" [16 p.62]. This interaction, according to Magedanz, Rothermel and Krause [17] can range from adaptive user interfaces to communities of intelligent processes (commonly referred to as cooperative agents). Many definitions, however, exist for the term 'Intelligent Agent' (see Table 1).

\begin{tabular}{|l|}
\hline Intelligent Agent Definition \\
\hline "Is either conceptualised or implemented using \\
concepts that are more usually applied to \\
humans." [18 p.117] \\
\hline "Learn about their observations to improve \\
their performances over time" [19 p.42] \\
\hline "programs that act on behalf of their human \\
users to perform laborious information- \\
gathering tasks." [20 p.36] \\
\hline "Consisting of a sensing element that can \\
receive events, a recognizer or classifier that \\
determines which event occurred, a set of logic \\
ranging from hard-coded programs to rule- \\
based inferencing, and a mechanism for taking \\
action." [21 p.2] \\
\hline "AI systems that interact with humans, each \\
other, and their virtual environment." [22 p.15] \\
\hline "Intelligent agents continuously perform three \\
functions: perception of dynamic conditions in \\
the environment; action to affect conditions in \\
the environment; and reasoning to interpret \\
perceptions, solve problems, draw inferences, \\
and determine actions." [23 p.22] \\
"Intelligent agents are software programs \\
designed to act autonomously and adaptively to \\
achieve goals defined by their human \\
developers or runtime users (the latter can be \\
other intelligent agents)." [24 p.91] \\
"An intelligent agent is an encapsulated \\
computer system that is situated in some \\
environment, and that is capable of flexible and \\
autonomous action in that environment in \\
order to meet its design objectives" [25 p.3] \\
Table 1: Overview of Definitions in Literature \\
and
\end{tabular}

Across the definitions presented in Table 1, there are some key characteristics which are commonplace and depict flexibility including: autonomy, social ability, reactivity, and/or pro-activeness [26]. Autonomy is defined as an agent's ability to "operate without the direct intervention of humans or others" and having "some kind of control over their actions and internal state" [18 p.4]. When "intelligent agents are capable of interacting with other agents (and possibly humans) in order to satisfy their design objectives", it is said that is has social ability [18 p.8].
Reactivity reflects intelligent agents that "are able to perceive their environment, and respond in a timely fashion to changes that occur in it in order to satisfy their design objectives" [18 p.8]. Intelligent agents which "are able to exhibit goal-directed behavior by taking the initiative in order to satisfy their design objectives" demonstrate pro-activeness [18 p.8].

It is argued that robots possess a number of these characteristics [27]. They perceive their environment and take actions in the environment to achieve their objectives and can include humanoid robots, unmanned rovers, entertainment pets, and drones for example [28]. Therefore, the context in which robots are used is important. A robot within a healthcare context promotes or monitors health, "assisting with tasks that are difficult to perform due to health problems or preventing further health decline. Health in this sense encompasses not just physical but mental, emotional and psychosocial problems" [29 p.576].

Healthcare robots can have many different functions and can be categorized as robots for patient safety (areas such as medical simulation and mechatronic devices for operating rooms) and rehabilitation and assistive robots (e.g. conventional therapy and robot-aided therapy, assistive robots) [30, 31]. For example, robots have been used to assist with brain surgeries (e.g. PUMA 200 system), in the area of orthopaedics (e.g. ROBODOC) and telesurgery (e.g. AESOP) [32]. Most of the robotic agents in this category, however, cannot be regarded as intelligent, because they are not endowed with autonomy, social ability, reactivity or pro-activeness, and are best described not from the Artificial Intelligence but from the mechatronics point of view [33]. There are some examples of intelligent agents in the areas of rehabilitation and assistive living. Assisting people at home is the goal of systems such as Guido, ALISA, Care-O-Bot and Pearl, which can, inter alia, inform nearby objects, monitor symptoms, fetch objects etc. [29]. The conversational humanoid robot MARKO [34] is an example of a rehabilitation robot for therapeutic exercises for children with cerebral palsy. Applying robotics in mental health is also an active research area [35] and targets topics such as autism spectrum disorder, activity engagement and physical exercise, dementia or schizophrenia with varied levels of intelligence endowed among different projects.

Within healthcare, an important aspect determining the success of an interaction between a human and a robot, is users' willingness to engage with the device [36] or human-robotic interactions. As noted in [35], robots can range in presentation "from very mechanical-looking to very anthropomorphic in appearance". Therefore, the presentation of robots to users (i.e. perceived design features) can also have an 
impact on whether the public trusts the system or not $[37,38]$. The next section discusses the trusting intentions towards robots.

\section{Trusting Intentions towards Robots}

As a concept trust is difficult to define. Indeed, the term "trust" is confusing [39] and broad [40]. According to Mayer, Davis and Schoorman [41 p.712] trust is the "willingness of a party to be vulnerable to the actions of another party based on the expectation that the other will perform a particular action important to the trustor, irrespective of the ability to monitor or control that other party". Many trust theorists have stated that trust develops over time [42]. However with further empirical work, researchers have observed surprisingly higher than expected levels of trust at an early stage of engagement [43].

The concept of trust is explored by McKnight, Cummings and Chervany [44] in their Initial Trust Model. This model characterizes trusting beliefs and trusting intentions based on three pillars, these include: personality-, institution-, and cognitionbased research which can provide justifications for varying levels of trust in individuals. Personalitybased trust develops during childhood as a child seeks and receives support from a caregiver/guardian [45, 46]. Institution-based trust reflects the security one feels about a situation because of the guarantees and other structures in place to create a sense of protection $[39,47]$. Cognition-based trust emphasizes first impressions, as opposed to personal interactions [46]. This work predominantly focuses on trusting humans. In recent years, academics have started to move beyond examining the human perspective to focus their attention on trusting beliefs and intentions towards technology [4, 49, 50, 51]

Trusting intention, also referred to as willingness to depend, occurs when an individual consciously chooses to overlook doubts about the target technology with the intention of moving forward to use [4, 52]. Trusting belief in technology has an impact on trusting intention [4]. Individuals with high trusting beliefs subscribe to the assertion that the technology offers benefits that may be relied upon in the future [4]. However, existing research presents mixed views regarding humans trusting intentions towards robots. Lee and See [53] define trust in terms of human-robotic interaction and they draw similar relationships to trusting in humans. Others studies suggest that trust in human-robot interaction is not the same as human-to-human trust [54]. Jian et al. [55] found that people are more willing to rate an automaton than a human using terms such as "distrusted". Thus, suggesting that there are differences between human trust in automations and human trust in humans.

We considered existing research that examines trusting intentions towards robots (see Table 2). RoboAdvisor Chatbots (defined as web-based systems that offer professional financial advice to private households at low-cost) were investigated within the investment decision making domain to explore how different levels of anthropomorphic design might compensate for the lack of human involvement and positively affect users' trusting beliefs and likeliness to follow its recommendations [56]. Prakash and Das [11] investigated the factors influencing consumer's trust in AI-based health chatbots (defined as AI-based algorithm that can conduct an intelligent conversation in auditory or textual format regarding) with the focus on social presence, perceived usefulness, safety risk, and propensity to trust. Therapeutic robots are socially assistive robotics that engage in social interaction with humans and that assist people [57]. Coeckelbergh et al. [57] examined if parents/ guardians should trust robots to engage with their children in a manner that enables the robot to operate effectively. Persuasive Robots which are used to support people in changing their attitudes and behaviours have also been examined from a trust perspective within the Charity domain [58]. The authors extended the technology acceptance model by including measures of trusting belief, compliance, liking, and psychological reactance. Within the education domain, one study [59] examined the effect of perceived accuracy and agency on the trust in teaching machines which are either social robots or inanimate machines. Assistive robots have been examined to investigate the influence of trust and anthropomorphism of robots on the willingness to have robots as coworkers [60].

\begin{tabular}{|c|c|}
\hline Robot /Ref & Trust Perspective \\
\hline $\begin{array}{l}\text { Robo- } \\
\text { Advisor } \\
\text { Chatbot } \\
{[56]}\end{array}$ & $\begin{array}{l}\text { Level of Anthropomorphism and } \\
\text { Perceived Social Presence }> \\
\text { Trusting Beliefs > Likeliness to } \\
\text { Follow Advice }\end{array}$ \\
\hline $\begin{array}{l}\text { Health chat } \\
\text { bot [11] }\end{array}$ & $\begin{array}{l}\text { System related factors (Social } \\
\text { presence, perceived usefulness, } \\
\text { perceived ease of use), Trust cue } \\
\text { (Third-party endorsements), } \\
\text { Risk factors (privacy risk, safety } \\
\text { risk), user0related factors } \\
\text { (propensity to trust technology) } \\
\text { > Trusting Beliefs > Willingness } \\
\text { to Depend. }\end{array}$ \\
\hline $\begin{array}{l}\text { Therapeutic } \\
\text { robot [57] }\end{array}$ & $\begin{array}{l}\text { Ethical Acceptability, } \\
\text { Replacement, and Autonomy; } \\
\text { Safety and Trust; Social }\end{array}$ \\
\hline
\end{tabular}




\begin{tabular}{|l|l|}
\hline & $\begin{array}{l}\text { Interaction; Emotions and } \\
\text { Attachment; Quality of the } \\
\text { Therapy; Privacy and Data } \\
\text { Protection > Trust }\end{array}$ \\
\hline $\begin{array}{l}\text { Socially } \\
\text { assistive } \\
\text { robots [11] }\end{array}$ & $\begin{array}{l}\text { Social influence, Performance } \\
\text { expectancy, effort expectancy, } \\
\text { facilitating conditions, trust, } \\
\text { privacy concerns, ethical } \\
\text { concerns, legal concerns }> \\
\text { Intentions to use }\end{array}$ \\
\hline $\begin{array}{l}\text { Robot bar } \\
\text { tenders } \\
{[61]}\end{array}$ & $\begin{array}{l}\text { Faith in Technology, Trusting } \\
\text { Stance, Negative Attitude, Robot } \\
\text { Form > Trusting Belief }> \\
\text { Trusting Intention }\end{array}$ \\
\hline $\begin{array}{l}\text { Service } \\
\text { robots [62] }\end{array}$ & $\begin{array}{l}\text { Institution-based trust } \\
\text { (Structural Assurance, } \\
\text { Situational Normality) }>\text { Trust in } \\
\text { service roots (performance, } \\
\text { process, purpose) }>\text { Intention to } \\
\text { stay in the hotel. }\end{array}$ \\
\hline
\end{tabular}

Table 2: Trusting intentions towards robots

The majority of these studies have been published recently, thus highlighting the novelty and apparent increase in focus on humans' trusting intentions towards intelligent agent technology. While many studies have explored trust, a dearth of research focuses on the contextual factors that drive the trust of anthropomorphic and/or system-like robotic features in healthcare [11]. The significance of context in IS research is well advocated in literature [63-65] and will provide richer insights into the design and development of robots for healthcare purposes.

We develop a theoretical framework for exploring the contextual factors which impact patients' trusting intentions towards robots in healthcare. To achieve this objective, three research questions are proposed:

Research Question 1: To what extent does anthropomorphic features impact trusting intentions towards robots in healthcare?

Research Question 2: To what extent does system-like features impact trusting intentions towards robots in healthcare?

Research Question 3: What contextual factors impact perceived anthropomorphic or system-like robotic qualities in healthcare?

\section{Theoretical framework}

This section develops a theoretical framework (Figure 1), with 7 propositions, investigating trusting intentions towards intelligent agents in healthcare. We build on and extend the work of Lankton, McKnight, and Tripp [4] to identify the antecedent to human-like trust (termed anthropomorphic features) and systemlike trust of intelligent agents within a healthcare context. As healthcare arguably possesses a unique context compared with its counterparts (e.g. manufacturing, retail), it is important to explore this discipline. In doing so, some work is borrowed by the healthcare discipline and applied in this research to ensure that this research is contextual in nature. According to Truex, Holmström, and Keil [66], borrowing theories from another discipline may translate to a more informed theory in IS research.

\subsection{Anthropomorphic versus System-Like Features}

Research argues that virtual (e.g. avatars) and physical (e.g. robotic) appearances positively affect users' perceptions of social characteristics in IAenabled systems [2]. It is therefore widely proposed that intelligent agents should be 'humanized' or made anthropomorphic to increase users' trusting intentions towards it $[67,68]$. Anthropomorphism is defined as a process of attributing mind, intentions, effortful thinking, emotional states, consciousness and behaviors to non-human entities $[69,70]$. The rationale behind humanizing non-human entities stems from the fact that as humans, we seem to have a natural tendency to attribute social meaning to the world in which we live [71]. This can potentially be achieved by embedding human-like trust concepts (e.g. benevolence, integrity, and ability) into intelligent agents [4]. Benevolence reflects the belief that the trustee will want to do good to the trustor, aside from an egocentric profit motive [4,41,72]; Integrity refers to the belief that a trustee adheres to a set of principles that the trustor finds acceptable $[4,41]$ whereas ability reflects the belief that the trustee has the ability to do what the trustor needs to have done $[52,73]$. These three dimensions have been assessed in various IS contexts [4] and have been found to fit into the trust nomological network and influence behavioral beliefs. Therefore, it is proposed:

P1: A technology that is perceived to have anthropomorphic features will impact trusting intentions towards robots in healthcare.

Conversely, a theory from the social psychology literature (called automation bias) proposes that some humans trust computer systems (i.e. automated decision-making) over other humans [54]. Research argues that intelligent agents are a technological artefact and should not be portrayed as something else (i.e. humanized) [74]. Followers of this perspective propose that computer systems should embed systemlike trust constructs (e.g. reliability, functionality, and helpfulness) $[4,52,72,73]$. Functionality refers to the extent to which users consider whether the technology 
provides sufficient features to complete a given task $[4,49]$; Reliability is the belief that the specific technology will consistently operate properly [49] and Helpfulness is the belief that the specific technology provides adequate and responsive help for users [4, 49]. These three dimensions of trust have been assessed in various IS contexts and have also been found to fit into the trust nomological network and influence behavioral beliefs [4,51].

Therefore, it is proposed:

P2: A technology that is perceived to have system-like features will impact trusting intentions towards robots in healthcare.

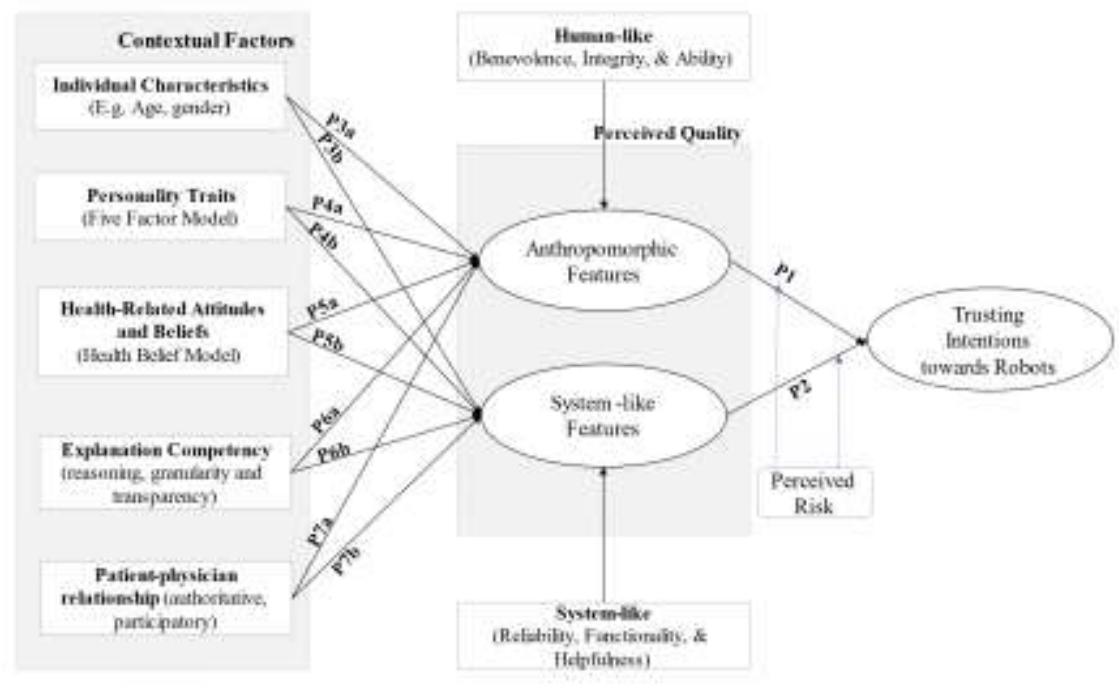

Figure 1: Contextual Factors Impacting Patients' Trusting Intentions towards Robots in Healthcare

\subsection{Antecedents of [de]anthropomorphism}

The tendency to anthropomorphize non-human entities is pervasive among humans, but there exists a high degree of inter-individual variability [71] due to factors such as age, gender, culture, and the nature of non-human entities. Individual characteristics reflect the various socio-demographic variables associated with patients. Some of these characteristics are shown to impact robot use [75]. It is proposed:

P3a: Individual characteristics will impact the perceived anthropomorphic quality of robots.

P3b: Individual characteristics will impact the perceived system-like quality of robots.

Personality traits have also been reported to influence behaviour [76], especially when interacting with technological artefacts [77-81]. The five-factor model of personality traits includes conscientiousness, extraversion, agreeableness, neuroticism, and openness to experience [82]. Conscientiousness is the degree to which a person is thorough, dependable and, responsible [83]; Extraversion is characterised by sociability, assertiveness and gregariousness [81]; Agreeableness is the extent to which an individual reflects kindness, good-naturedness, trust, and tolerance [81-83]; Neuroticism is the extent to which an individual is anxious, depressed, angry, embarrassed, emotional, worried, and insecure [81-83]; Openness to experience is characterised by curiosity, originality, inquisitiveness, and artistic sensitivity [81-83]. Extraversion traits are important in developing a more complete model of how individuals interact with technology [81]. Personality traits could have an impact on the anthropomorphism (or not) personalisation of intelligent agents in healthcare. It is proposed:

P4a: Personality Traits will impact the perceived anthropomorphic quality of robots.

P4b: Personality Traits will impact the perceived systems-like quality of robots.

The health belief model [84] focuses on the attitudes and beliefs of individuals when they are required to take a health-related action. This model focuses on perceived susceptibility, perceived severity, perceived benefits, perceived barriers, and cues to action which account for people's readiness to act. In this model, perceived susceptibility refers to the "subjective risks of contracting a condition" [84-86]. As a result, individuals may respond differently even if they are presented with the same facts or statistics, and this may influence the perceived design features of robotics. Perceived severity reflects an individual's conviction regarding the seriousness of a given health problem [84-86]. Individuals may prefer to experience a more social/human experience when diagnosing and treating 
a serious illness and may favor anthropomorphic features. Perceived benefits refer to an individual's beliefs regarding the relative effectiveness of an action to reduce the disease threat. In this context, it refers to an individual belief in the perceived effectiveness of robotic design [84-86]. Perceived barriers reflects actions which are perceived as inconvenient or unpleasant to the user [84-86]. Cues to action are triggers that make the individual take action, such as education and advice from others [84-86]. It is proposed:

P5a: Health-belief characteristics will impact the perceived anthropomorphic quality of robots.

P5b: Health-belief characteristics will impact the perceived system-like quality of robots.

Medical professionals need to be able to justify and explain a clinical decision to their patients [87, 88]. In doing so, this process builds trust between the patient and the healthcare provider [89-91]. Yet, intelligent agents are considered a 'black box' to providing justifications and explanations [92], receiving inputs and providing outputs, without sufficient reasoning, granularity, and transparency [93]. Explanations "require the system, or the expert who relies on it, to reveal how a finding or a decision is grounded in two kinds of knowledge: a "domain model" in which causal relationships are captured and "domain principles" that lay out the "how to" knowledge or the dynamics of the domain in question" [94]. This allows agents to make decisions or provide tailored advice. The transparency of the systems' decisions, including the provision of explanations influences users' perceptions [2, 27]. It is proposed:

P6a: Explanation Competency will impact the perceived anthropomorphic quality of robots.

P6b: Explanation Competency will impact the perceived systems-like quality of robots.

The type of patient-physician relationship may have an impact on anthropomorphizing (or not) AI in healthcare. Patient-physician communication is a fundamental cornerstone when delivering healthcare and when done well, such communication produces a therapeutic effect for the patient [95]. As a result, some people may perceive anthropomorphic features more impactful than system-like qualities. The patientprovider communication literature reveals that patients may view their relationship with the provider as authoritative or participatory [96]. Given that robots may interfere with this relationship, this dynamic may also impact trusting intentions. It is proposed:

P7a: Existing patient-physician relationships will impact the perceived anthropomorphic quality of robots.

P7b: Existing patient-physician relationships will impact the perceived system-like quality of robots.
Finally, perceived risk is inherently linked with trusting intentions, see Figure 1. Risk, in general, means the perceived probability of loss or harm [97]. Perceived risk means the extent to which a user believes it is unsafe to use the robot or that negative consequences are possible [98]. Once users perceive risk more than benefits, they could completely avoid the use of robots [99]. Moreover, researchers [100, 101] have argued for the inclusion of Perceived Risks in assessing the intention toward robots. The impact of these factors on [de]anthropomorphism and subsequent trusting intentions towards robots has gone unexplored to date.

\section{Research Plan}

Future research will involve empirically examining the proposed theoretical model using an exploratory sequential mixed methods approach and a series of vignettes. Both qualitative and quantitative strands of research under the mixed method methodology can be performed in concurrent or sequential phases [102]. Applying the former approach will result in the parallel or simultaneous collection and analysis of data, whereby the process commences and finishes at approximately the same time or with a minor time lapse. The latter involves the collection and analysis of data in chronological order, whereby one component emerges from or is dependent on the previous component [103]. A qualitative approach this will enable us to refine the model and propositions (See Figure 1) into hypotheses for further testing. Any new, emerging factors will be incorporated into the model for further evaluation via questionnaire.

While vignettes are widely used within the healthcare research domain [97], this approach has also been used in IS [cf. 98, 99] and across other social sciences. The methodology of vignettes for conducting this research "consists of short descriptive scenarios and/or images to engage patients in hypothetical situations in which their emotional, psychological, and sociological responses can be measured" [100 p.451]. The use of vignettes is important in this context for several reasons. First, as most of the participants will not have previously interacted with intelligent agents in healthcare, it is important to situate them within a hypothetical situation for them to appreciate the context. Second, intelligent agents can present in many formats in healthcare (e.g. chatbots versus surgical robot). Our initial intentions are to capture participants' perceptions on their potential interaction with chatbots/avatars for primary healthcare services.

A user-centred approach, which engages with endusers early in the development lifecycle, is of utmost importance for the successful adoption and long-term use of any technological innovation [104]. Our aim is to 
engage citizens with a range of socio-demographic backgrounds. Various media campaigns will be employed to attract participants to this study.

The use of a mixed-methods approach, in conjunction with vignettes, will help us to develop, refine, and test our theoretical model. This will focus on citizens' perceived trusting intentions towards robots based on the interaction of humans and robots within a hypothetical contextual landscape of delivering healthcare services. We plan to test the model on citizens' actual trusting intentions towards robots based on the interaction of humans and robots within the contextual landscape of delivering healthcare services. This will involve citizens' engaging with actual robots (e.g. interacting with chatbot prototypes with anthropomorphic or system-like features or those used in hospitals) using a design science approach. The data obtained will provide rich insights into the design and development of robots across a series of patient profiles and medical areas. This will create new insights between the perceived and actual trusting intentions towards robots and how best we can design and personalise robots for individuals going forward. It will help the researchers identify the balance between anthropomorphic and system like features based on the contextual landscape in which individuals are required to interact with intelligent agents. Examining the actual trusting intentions will further require the researchers to consider decomposing the trust constructs to examine that of institutional trust, as trust may not entirely depend on the history between two individuals but rather on the norms of an institution (i.e. focusing on concerns about institutions being sincere and ethical) [105].

\section{Conclusion}

The use of intelligent agents (e.g. robots) in a variety of sectors is expected to dramatically increase in the next decade [1]. This advanced technology is being used in financial services [53], tourism [60], and to support and enhance the care of the elderly [11], leading to a proliferation of human-robot interactions. There has been a recent increase in the adoption of IA in specialist areas of healthcare. While the use of this technology is lauded as a new opportunity to promote, enhance and monitor health and assist in the delivery of patient care, little is known about the contextual factors that drive the trust of anthropomorphic and/or system-like robotic features in healthcare [11].

Future research should use the proposed theoretical model as a basis of further qualitative and quantitative evaluation. It is imperative to gather data across a range of contexts, however, to assist with the generalisability of the findings. These findings will support robot designers and developers to design, develop, personalise, and implement accessible technologies that are trustworthy and fit for purpose. Improved design will maximise the benefits of these technologies for users, subsequently creating a greater return on investment for organisations.

\section{References}

[1] Jones, L., et al., Artificial intelligence, machine learning and the evolution of healthcare: A bright future or cause for concern? Bone \& joint research, 2018. 7(3): p. 223-225.

[2] Rzepka, C. and B. Berger, User interaction with AIenabled systems: a systematic review of IS research, in Thirty Ninth International Conference on Information Systems. 2018: San Francisco.

[3] Edwards, C., et al., Is that a bot running the social media feed? Testing the differences in perceptions of communication quality for a human agent and a bot agent on Twitter. Computers in Human Behavior, 2014. 33: p. 372-376.

[4] Lankton, N.K., D.H. McKnight, and J. Tripp, Technology, humanness, and trust: Rethinking trust in technology. Journal of the Association for Information Systems, 2015. 16(10): p. 1.

[5] Rosenthal-Von Der Pütten, A.M., et al., Investigations on empathy towards humans and robots using fMRI. Computers in Human Behavior, 2014. 33: p. 201-212.

[6] Rosenthal-Von Der Pütten, A.M. and N.C. Krämer, How design characteristics of robots determine evaluation and uncanny valley related responses. Computers in Human Behavior, 2014. 36: p. 422-439.

[7] Mori, M., The uncanny valley. Energy, 1970. 7(4): p. 33-35.

[8] Mori, M., K.F. MacDorman, and N. Kageki, The uncanny valley [from the field]. IEEE Robotics \& Automation Magazine, 2012. 19(2): p. 98-100.

[9] Ho, C.-C. and K.F. MacDorman, Measuring the uncanny valley effect. International Journal of Social Robotics, 2017. 9(1): p. 129-139.

[10] Riemer, K. and J. Kay. Mapping beyond the uncanny valley: A Delphi study on aiding adoption of realistic digital faces. in Proceedings of the 52nd Hawaii International Conference on System Sciences. 2019.

[11] Prakash, A.V. and S. Das. Would you Trust a Bot for Healthcare Advice? An Empirical Investigation. in PACIS. 2020.

[12] Nadarzynski, T., Miles, O., Cowie, A., \& Ridge, D. Acceptability of artificial intelligence (AI)-led chatbot services in healthcare: A mixed-methods study. Digital health, $\quad 2019, \quad 5, \quad 2055207619871808$. https://doi.org/10.1177/2055207619871808.

[13] Pino, M., et al., "Are we ready for robots that care for us?" Attitudes and opinions of older adults toward 
socially assistive robots. Frontiers in aging neuroscience, 2015. 7: p. 141.

[14] Rydgren, M., Humanoid robots in healthcare: A quantitative study about students' attitudes. 2020.

[15] Charishma, D. and D.S. Ganesh, Intelligent Agents in Distributed Data Mining. International Journal of Research Studies in Science, Engineering and Technology, 2016. 3(3): p. 12-17.

[16] Carmel, D. and S. Markovitch. Learning models of intelligent agents. in AAAI/IAAI, Vol. 1. 1996.

[17] Magedanz, T., K. Rothermel, and S. Krause. Intelligent agents: An emerging technology for next generation telecommunications? in Proceedings of IEEE INFOCOM'96. Conference on Computer Communications. 1996. IEEE.

[18] Wooldridge, M. Intelligent agents: The key concepts. in ECCAI Advanced Course on Artificial Intelligence. 2001. Springer.

[19] Isern, D. and A. Moreno, A systematic literature review of agents applied in healthcare. Journal of medical systems, 2016. 40(2): p. 43.

[20] Sycara, K., et al., Distributed intelligent agents. IEEE expert, 1996. 11(6): p. 36-46.

[21] Seydim, A.Y., Intelligent agents: A data mining perspective, Southern Methodist University, Dallas, 1999,http://citeseerx.ist.psu.edu/viewdoc/download?d oi=10.1.1.23.7628\&rep=rep1\&type $=$ pdf

[22] Tambe, M., et al., Intelligent agents for interactive simulation environments. AI magazine, 1995. 16(1): p. 15-15.

[23] Franklin, S. and A. Graesser. Is it an Agent, or just a Program?: A Taxonomy for Autonomous Agents. in International Workshop on Agent Theories, Architectures, and Languages. 1996. Springer.

[24] Haynes, S.R., M.A. Cohen, and F.E. Ritter, Designs for explaining intelligent agents. International Journal of Human-Computer Studies, 2009. 67(1): p. 90-110.

[25] Mangina, E. and I.P. Vlachos, Intelligent Optimisation Agents in Supply Networks. 2003.

[26] Winikoff, M., JACK ${ }^{\mathrm{TM}}$ intelligent agents: an industrial strength platform, in Multi-Agent Programming. 2005, Springer. p. 175-193.

[27] Bekey, G.A., On autonomous robots. Knowledge Engineering Review, 1998. 13(2): p. 143-146.

[28] Rubio, F., F. Valero, and C. Llopis-Albert, A review of mobile robots: Concepts, methods, theoretical framework, and applications. International Journal of Advanced Robotic Systems, 2019. 16(2): p. 1729881419839596.

[29] Robinson, H., B. MacDonald, and E. Broadbent, The role of healthcare robots for older people at home: A review. International Journal of Social Robotics, 2014. 6(4): p. 575-591.

[30] Gross, H.-M., et al. Robot companion for domestic health assistance: Implementation, test and case study under everyday conditions in private apartments. in 2015 IEEE/RSJ International Conference on Intelligent Robots and Systems (IROS). 2015. IEEE.

[31]Kim, J., G.M. Gu, and P. Heo, Robotics for healthcare, in Biomedical Engineering: Frontier Research and Converging Technologies. 2016, Springer. p. 489-509.

[32] Hussain, A., et al., The use of robotics in surgery: a review. International journal of clinical practice, 2014. 68(11): p. 1376-1382.

[33] Najarian, S., et al., Mechatronics in medicine a biomedical engineering approach. 2011: McGraw-Hill Professional.

[34] Gnjatović, M., et al. Pilot corpus of child-robot interaction in therapeutic settings. in 2017 8th IEEE International Conference on Cognitive Infocommunications (CogInfoCom). 2017. IEEE.

[35] Riek, L.D., Robotics technology in mental health care, in Artificial intelligence in behavioral and mental health care. 2016, Elsevier. p. 185-203.

[36] Tanioka, T., M.C. Smith, and Y. Zhao, Framing the Development of Humanoid Healthcare Robots in Caring Science. International Journal for Human Caring, 2019. 23(2).

[37] Langer, A., et al., Trust in socially assistive robots: Considerations for use in rehabilitation. Neuroscience \& Biobehavioral Reviews, 2019. 104: p. 231-239.

[38] Matthews, G., et al., Individual Differences in Trust in Autonomous Robots: Implications for Transparency. IEEE Transactions on Human-Machine Systems, 2019. 50(3): p. 234-244.

[39] Shapiro, S.P., The social control of impersonal trust. American journal of Sociology, 1987. 93(3): p. 623658.

[40] Williamson, O.E., Calculativeness, trust, and economic organization. The journal of law and economics, 1993. 36(1, Part 2): p. 453-486.

[41] Mayer, R.C., J.H. Davis, and F.D. Schoorman, An integrative model of organizational trust. Academy of management review, 1995. 20(3): p. 709-734.

[42] Rempel, J.K., J.G. Holmes, and M.P. Zanna, Trust in close relationships. Journal of personality and social psychology, 1985. 49(1): p. 95-112.

[43] Lee, W.-H., C.-W. Lin, and K.-H. Shih, A technology acceptance model for the perception of restaurant service robots for trust, interactivity, and output quality. International Journal of Mobile Communications, 2018. 16(4): p. 361-376.

[44] McKnight, D.H., L.L. Cummings, and N.L. Chervany, Initial trust formation in new organizational relationships. Academy of Management review, 1998. 23(3): p. 473-490.

[45] Bowlby, J., Attachment and Loss. Vol. 1, Attachment. New York: Basic, 1982. Attachment and Loss. 2.

[46] Erikson, E.H., Identity: Youth and crisis. 1968: WW Norton \& company. 
[47] Zucker, L.G., Production of trust: Institutional sources of economic structure, 1840-1920. Research in organizational behavior, 1986. 8: p. 53-111.

[48] Brewer, M.B., Ethnocentrism and its role in interpersonal trust. Scientific inquiry and the social sciences, 1981. 214: p. 231.

[49] Mcknight, D.H., et al., Trust in a specific technology: An investigation of its components and measures. ACM Transactions on management information systems (TMIS), 2011. 2(2): p. 1-25.

[50] De Visser, E.J., et al., Almost human: Anthropomorphism increases trust resilience in cognitive agents. Journal of Experimental Psychology: Applied, 2016. 22(3), p.331.

[51] Tripp, J., D.H. McKnight, and N.K. Lankton. Degrees of Humanness in Technology: What Type of Trust Matters? in AMCIS. 2011.

[52] McKnight, D.H., V. Choudhury, and C. Kacmar, The impact of initial consumer trust on intentions to transact with a web site. Journal of strategic information systems, 2002. 11(3-4): p. 297-323.

[53] Lee, J.D. and K.A. See, Trust in automation: Designing for appropriate reliance. Human factors, 2004. 46(1): p. 50-80.

[54] Madhavan, P. and D.A. Wiegmann, Similarities and differences between human-human and humanautomation trust: an integrative review. Theoretical Issues in Ergonomics Science, 2007. 8(4): p. 277-301.

[55] Jian, J.-Y., A.M. Bisantz, and C.G. Drury, Foundations for an empirically determined scale of trust in automated systems. International journal of cognitive ergonomics, 2000. 4(1): p. 53-71.

[56] Morana, S., et al. The Effect of Anthropomorphism on Investment Decision-Making with Robo-Advisor Chatbots. in ECIS. 2020.

[57] Coeckelbergh, M., et al., A survey of expectations about the role of robots in robot-assisted therapy for children with ASD: ethical acceptability, trust, sociability, appearance, and attachment. Science and engineering ethics, 2016. 22(1): p. 47-65.

[58] Ghazali, A.S., et al., Persuasive Robots Acceptance Model (PRAM): roles of social responses within the acceptance model of persuasive robots. International Journal of Social Robotics, 2020: p. 1-18.

[59] Brink, K.A. and H.M. Wellman, Robot teachers for children? Young children trust robots depending on their perceived accuracy and agency. Developmental Psychology, 2020. 56(7): p. 1268.

[60] Erebak, S. and T. Turgut, Caregivers' attitudes toward potential robot coworkers in elder care. Cognition, Technology \& Work, 2019. 21(2): p. 327336.

[61] Tussyadiah, I.P., F.J. Zach, and J. Wang, Do travelers trust intelligent service robots? Annals of Tourism Research, 2020. 81(C).
[62] Park, S., Multifaceted trust in tourism service robots. Annals of Tourism Research, 2020. 81: p. 102888.

[63] Avgerou, C., The significance of context in information systems and organizational change. Information systems journal, 2001. 11(1): p. 43-63.

[64] Hong, W., et al., A framework and guidelines for context-specific theorizing in information systems research. Information Systems Research, 2014. 25(1): p. 111-136.

[65] Chiasson, M.W. and E. Davidson, Pushing the contextual envelope: developing and diffusing IS theory for health information systems research. Information and Organization, 2004. 14(3): p. 155188.

[66] Truex, D., J. Holmström, and M. Keil, Theorizing in information systems research: A reflexive analysis of the adaptation of theory in information systems research. Journal of the Association for Information Systems, 2006. 7(1): p. 33.

[67] Riedl, R., et al., Trusting humans and avatars: A brain imaging study based on evolution theory. Journal of Management Information Systems, 2014. 30(4): p. 83114.

[68] Nowak, K.L. and Rauh, C., The influence of the avatar on online perceptions of anthropomorphism, androgyny, credibility, homophily, and attraction. Journal of Computer-Mediated Communication, 2005. 11(1), pp.153-178.

[69] Epley, N., A. Waytz, and J.T. Cacioppo, On seeing human: a three-factor theory of anthropomorphism. Psychological review, 2007. 114(4): p. 864.

[70] Puzakova, M., J.F. Rocereto, and H. Kwak, Ads are watching me: A view from the interplay between anthropomorphism and customisation. International Journal of Advertising, 2013. 32(4): p. 513-538.

[71] Cullen, H., et al., Individual differences in anthropomorphic attributions and human brain structure. Social Cognitive and Affective Neuroscience, 2014. 9(9): p. 1276-1280.

[72] Lankton, N. and D.H. McKnight, Using expectation disconfirmation theory to predict technology trust and usage continuance intentions. Eli Broad College of Business, Minnesota, 2006.

[73] McKnight, D.H., Trust in information technology. The Blackwell encyclopedia of management, 2005. 7: p. 329-331.

[74] Kling, R. and S.L. Star, Human centered systems in the perspective of organizational and social informatics. ACM SIGCAS Computers and Society, 1998. 28(1): p. 22-29.

[75] De Graaf, M.M., S.B. Allouch, and T. Klamer, Sharing a life with Harvey: Exploring the acceptance of and relationship-building with a social robot. Computers in human behavior, 2015. 43: p. 1-14. 
[76] Mowen, J.C., The 3M model of motivation and personality: Theory and empirical applications to consumer behavior. 2000: Springer Science \& Business Media.

[77] Roberts, J.A., C. Pullig, and C. Manolis, I need my smartphone: A hierarchical model of personality and cell-phone addiction. Personality and Individual Differences, 2015. 79: p. 13-19.

[78] Ajibade, P., Technology acceptance model limitations and criticisms: Exploring the practical applications and use in technology-related studies, mixed-method, and qualitative researches. Library Philosophy \& Practice, 2018. 1941: p. 1-14.

[79] Minsky, B.D. and D.B. Marin, Why faculty members use e-mail: The role of individual differences in channel choice. The Journal of Business Communication (1973), 1999. 36(2): p. 194-211.

[80] El-Tah, Z.K.R. and M.-I.R.M. Jaradat, The big five personality traits and their relationship with the intensity of using Facebook: a developing country perspective. International Journal of Business Information Systems, 2018. 27(4): p. 512-537.

[81] Barnett, T., et al., Five-factor model personality traits as predictors of perceived and actual usage of technology. European Journal of Information Systems, 2015. 24(4): p. 374-390.

[82] Digman, J.M., Personality Structure-Emergence of the 5 Factor Model. Annual Review of Psychology, 1990. 41: p. 417-40.

[83] Barrick, M.R. and M.K. Mount, The big five personality dimensions and job performance: a metaanalysis. Personnel psychology, 1991. 44(1): p. 1-26.

[84] Hochbaum, G., I. Rosenstock, and S. Kegels, Health belief model. United states public health service, 1952: p. W432W8784.

[85] Ng, B.-Y., A. Kankanhalli, and Y.C. Xu, Studying users' computer security behavior: A health belief perspective. Decision Support Systems, 2009. 46(4): p. 815-825.

[86] Janz, N.K. and M.H. Becker, The health belief model: A decade later. Health education quarterly, 1984. 11(1): p. 1-47.

[87] Mattingly, C., What is clinical reasoning? American Journal of Occupational Therapy, 1991. 45(11): p. 979986.

[88] Mattingly, C., The narrative nature of clinical reasoning. American Journal of Occupational Therapy, 1991. 45(11): p. 998-1005.

[89] Hall, A., et al., Moving beyond 'safety'versus 'autonomy': a qualitative exploration of the ethics of using monitoring technologies in long-term dementia care. BMC geriatrics, 2019. 19(1): p. 145.

[90] Hall, M.A., et al., Trust in physicians and medical institutions: what is it, can it be measured, and does it matter? Milbank Quarterly, 2001. 79(4): p. 613-639.
[91] Epstein, R.M., et al., Measuring patient-centered communication in patient-physician consultations: theoretical and practical issues. Social science \& medicine, 2005. 61(7): p. 1516-1528.

[92] O' Connor, D. Wellcome Trust and Future Advocacy. 2018. Ethical, Social, And Political Challenges of Artificial Intelligence in Health". URL: https://wellcome.ac.uk/sites/default/files/ai-in-healthethical-social-political-challenges.pdf. 2018.

[93] Pieters, W., Explanation and trust: what to tell the user in security and AI? Ethics and information technology, 2011. 13(1): p. 53-64.

[94] London, A.J., Artificial intelligence and black-box medical decisions: accuracy versus explainability. Hastings Center Report, 2019. 49(1): p. 15-21.

[95] Travaline, J.M., R. Ruchinskas, and G.E. D'Alonzo Jr, Patient-physician communication: why and how. Journal of the American Osteopathic Association, 2005. 105(1): p. 13.

[96] Muzumdar, J.M., et al., Effects of anthropomorphic images and narration styles in promotional messages for generic prescription drugs. Research in Social and Administrative Pharmacy, 2013. 9(1): p. 60-79.

[97] Rousseau, D.M., et al., Not so different after all: A cross-discipline view of trust. Academy of management review, 1998. 23(3): p. 393-404.

[98] Sanders, T., et al. A model of human-robot trust: Theoretical model development. in Proceedings of the human factors and ergonomics society annual meeting. 2011. SAGE Publications Sage CA.

[99] Hancock, P.A., et al., A meta-analysis of factors affecting trust in human-robot interaction. Human factors, 2011. 53(5): p. 517-527.

[100] Blut, M., N. WÃ̃ $1 / 4$ derlich, and C. Brock, Innovative Technologies in Branded-Service Encounters: How Robot Characteristics Affect Brand Trust and Experience. 2018.

[101] Ala'Al-Mahameed, M.A.-O. and J. PelegrínBorondo, Cyborg As A Surgeon, Societal Challenges in the Smart Society: p. 57.

[102] Tashakkori, A., R.B. Johnson, and C. Teddlie, Foundations of mixed methods research: Integrating quantitative and qualitative approaches in the social and behavioral sciences. 2020: SAGE Publications.

[103] Creswell, J.W., A concise introduction to mixed methods research. 2014: SAGE publications.

[104] Giaccardi, E. and J. Redström, Technology and more-than-human design. Design Issues, 2020. 36(4).

[105] Malle, B.F. and D. Ullman, A Multi-Dimensional Conception and Measure of Human-Robot Trust. 2020, Elsevier. 